PUBLISHED BY THE AMERICAN MUSEUM OF NATURAL HISTORY

CENTRAL PARK WEST AT 79TH STREET, NEW YORK, NY 10024

Number 3400, 14 pp., 13 figures

March 27, 2003

\title{
Developmental Abnormalities in Wild Populations of Birds: Examples from Lesser Snow Geese (Chen caerulescens caerulescens)
}

\author{
R.F. ROCKWELL, ${ }^{1}$ B.M. PEZZANITE, ${ }^{2}$ AND P. MATULONIS ${ }^{3}$
}

\begin{abstract}
Changes in the frequency of individuals with gross abnormalities can be used as an indicator of changes in the occurrence of biologically significant levels of developmental toxicants in the habitats of natural populations. The precise nature of the defects and their relative distribution can often provide clues as to the type of contamination. Such inferences clearly require baseline data on the frequency of such deformities, and that is the purpose of this paper. For Mid-continent lesser snow geese (Chen caerulescens caerulescens) nesting at La Pérouse Bay, the current rate of gross external abnormalities among embryos and near-hatch goslings at hatch is $3.937 \times 10^{-4}$ per egg (95\% confidence limits $1.7053 \times 10^{-4}$ to $6.507 \times 10^{-4}$ ) and is consistent with estimates made for other species in minimally or uncontaminated habitats. Among the abnormal specimens, however, the relative distribution of defects of the beak and eye is not consistent with rates of spontaneous abnormalities reported for chickens. If the higher relative frequency of beak defects persists in future or other geographic samples displaying overall levels of abnormalities higher than our benchmark, then contaminants acting as type 1 teratogens should be suspected. Of the compounds this increasingly agriculturally dependent species is exposed to, insecticides rather than herbicides would be the more likely class of candidates. We urge others who may have similar data on other species to make it more broadly available since such benchmarks are crucial for the use of birds as bioindicators of environmental conditions. To that end, we offer our web site as a place where data on and images of abnormal specimens can be posted and, within certain constraints, will curate submitted specimens.
\end{abstract}

\footnotetext{
${ }^{1}$ Research Associate, Division of Vertebrate Zoology (Ornithology), American Museum of Natural History; Professor of Biology, The City College of CUNY. e-mail: rfr@amnh.org

${ }^{2}$ Student, Division of Vertebrate Zoology (Ornithology), American Museum of Natural History. e-mail: bpez@amnh.org

${ }^{3}$ Student, Division of Vertebrate Zoology (Ornithology), American Museum of Natural History. e-mail: pzm@amnh.org
} 


\section{INTRODUCTION}

Developmental abnormalities can result from random accidents of ontogeny, single mutations, inbreeding, nutritional constraints, climatic factors, or the action of compounds with teratogenic effects (Romanoff, 1972). A clear example of the teratogenic action of an environmental contaminant was seen at Kesterson National Wildlife Refuge in 1983 where embryos and hatchlings from $16 \%$ of the eggs of several aquatic bird species displayed gross anatomical abnormalities (Hoffman et al., 1988). These birds were occupying portions of the refuge where levels of selenium were more than 100 times those in control areas (Ohlendorf et al., 1986, 1988; Hoffman et al., 1988). Similar situations have been reported for the Great Lakes where, in 1988 for example, deformed embryos and hatchlings were found among 6$15 \%$ of Double-crested Cormorant (Phalacrocorax auritus) and 3-28\% of Caspian Tern (Sterna caspia) eggs sampled from sites displaying elevated levels of persistent organochlorine contaminants (PCDDs, PCDFs, PCBs, and DDEs) (Yamashita et al., 1993; Ludwig et al., 1995, 1996; Custer et al., 1999). Other such examples are summarized in Fox et al. (1991b) and Rykman et al. (1998).

These exceptionally high rates of gross abnormalities in aquatic bird species were among the first indicators that compounds accumulating in these habitats had reached biologically problematic levels. Since a multitude of compounds with potential teratogenic action persist or continue to accumulate in the environment (e.g., McGinn, 2000; Officer and Page, 2000; Hoffman et al., 2001; Pimm, 2001), it is important to continue monitoring a variety of wild populations for abnormalities. On the one hand, we need to be vigilant in monitoring the health of species. On the other hand, the detection of differences in abnormality rates among habitats or of temporally changing rates of abnormalities in general may serve as an early warning of biologically significant environmental deterioration (or improvement) of specific or general habitats. Using birds as bioindicators of environmental change has a long and successful history (e.g., Peakall and
Boyd, 1987; Fox and Weseloh, 1987; Fox et al., 1991a, 1991b; Rykman et al., 1998).

In some cases, observed rates of deformity in suspected habitats can be compared to those in less or putatively uncontaminated control areas. This was the approach taken at Kesterson National Wildlife Refuge where rates of deformity in the contaminated area were compared with those at an uncontaminated control site, the Volta Wildlife Area (Ohlendorf et al., 1986, 1988; Hoffman et al., 1988). Similar spatial comparisons were used, for example, in examining deformities and contaminants in Double-crested Cormorants, Herring Gulls (Larus argentatus) and both Caspian and Forster's Terns (Sterna caspia and S. forsteri) (Hoffman et al., 1987; Fox et al., 1991b; Gilbertson et al., 1991; Yamashita et al., 1993; Larson et al., 1996; Blus et al., 1998; Rykman et al., 1998).

Unfortunately, control sites as such may not always be available. In some cases, there may be no clear indication of what the potential contaminant is, so identifying an appropriate control site is simply not possible. Alternatively, the contaminants may be so widespread that an uncontaminated (or even less contaminated) site simply does not exist. While a correlation between rates of deformity and degree of contamination among sites varying in assayed contaminants provides some insights, results are complex since sites often differ in which contaminants are present. Further, assigning causality is usually complicated by the presence of complex mixtures of contaminants, often with spatially correlated concentrations (e.g., Yamashita et al., 1993; Geisy et al., 1994; Ludwig et al., 1995, Nisbet, 1998; Custer et al., 1999).

As an alternative, rates of spontaneous abnormalities occurring in the absence of teratogenic compounds could be used as points of reference for current estimates (Hays and Risebrough, 1972; Romanoff, 1972). Unfortunately, baseline rates from controlled studies are not available for many species. Beyond that, there is no guarantee that spontaneous abnormality rates for model species such as domestic chickens or for any species obtained under controlled conditions are appropriate reference points for populations of various species in natural habitats. 
Abnormality rates can be estimated for species currently occupying natural habitats. Owing to the present state of the environment, however, such "current" abnormality rates may not reflect true baseline (no contaminant) abnormality levels but rather serve as contemporary abnormality rate benchmarks. As noted by Fox et al. (1991b: 159), "If the incidence and prevalence of these malformations were monitored routinely, they could serve as sensitive indicators of the possible prevalence of biologically significant concentrations of developmental toxicants in the food chain." Evaluations of changes among temporal samples of such rates for Double-crested Cormorants have been used in this fashion to monitor changes in environmental conditions in the Great Lakes (e.g., Fox et al., 1991b; Larson et al., 1996; Rykman et al., 1998), although inferences with respect to causal linkage to specific toxicants can again be complicated (e.g., Ludwig et al., 1995, Nisbet, 1998; Custer et al., 1999). More generally, and at the very minimum, an increase above a currently established benchmark rate would serve as an indicator that contamination has potentially reached a biologically critical level and such an increase could be used to warrant (and possibly justify funding of) direct screening of chemical contamination.

Because species differ in sensitivity to contamination (e.g., Ohlendorf et al., 1986, 1988; Hoffman et al., 1988), the use of abnormalities in birds as bioindicators of environmental change requires data from a variety of species (Peakall and Boyd, 1987; Gilbertson et al., 1987). Unfortunately, such benchmark values are not available for most wild populations primarily because the estimation of relatively rare events requires sample sizes so large that specific studies to establish benchmark abnormality levels would not likely be mounted or funded. However, such benchmark estimates could be made with little additional effort using data and specimens collected as part of other larger and long-term studies (e.g., Threlfall, 1968; Austin, 1969; Smith and Diem, 1971; Ryder and Chamberlain, 1972; Gochfeld, 1975; Nogales et al., 1990; Craves, 1994; Volponi, 1996; Custer et al., 1999). In addition to estimating the benchmark rates, it is important that such studies include detailed descriptions of the deformed specimens since the types of abnormalities can provide insight as to the identity of potential teratogenic agents (e.g., Landauer, 1967; Romanoff, 1972; Gilbertson et al., 1976; Hoffman and Albers, 1984; Hoffman, 1990).

In this paper, we present data on deformities in a wild population of Lesser Snow Geese (Chen caerulescens caerulescens, henceforth snow geese) nesting at La Pérouse Bay, near Churchill, Manitoba, Canada. These data were collected during a longterm ecological study of the species (Cooke et al., 1995). While these birds do not nest in an area that we know to be contaminated, they make extensive use of agricultural lands and industrialized coastal marshes during the winter and on both fall and spring migrations. These areas are (and have been) exposed to a variety of pesticides, herbicides, fungicides, and industrial toxicants (e.g., White et al., 1982; Flickenger and Bolen, 1979). Nutrients and any associated contaminants acquired by females feeding in late winter and early spring in those areas are transported north to the nesting grounds and the stored nutrients are used in producing eggs (e.g. Ankney and MacInnes, 1978). Since any contaminants transferred to the eggs could act as teratogenic agents, our data represent the current benchmark status for this wild population.

\section{METHODS}

Research on the breeding biology and population dynamics of snow geese at La Pérouse Bay $\left(58^{\circ} 43.5^{\prime} \mathrm{N}, 93^{\circ} 27.8^{\prime} \mathrm{W}\right)$ has been ongoing since 1969. Basic field procedures are summarized in Cooke et al. (1995). This study uses data from three sets of collections made during that study. As part of our general work, some nests each year were monitored daily, allowing, among other things, a precise estimate of the frequency of eggs and near-hatch goslings that were abandoned by parents who left the nesting area with their successful goslings. Abandoned eggs (pipped and not pipped) from those nests were collected the day after the hatched goslings left, and the precise status (e.g., infertile, embryo, near-hatch gosling) was recorded (set 1). A 
larger number of less intensively monitored nests were visited irregularly until hatching was detected. Those nests (referred to then as hatching nests) were revisited the next day and all abandoned eggs (pipped and not pipped) were collected (set 2). In three years (1989, 1994, and 1995), 2 pipping eggs were collected from each of approximately 100 randomly selected and otherwise successful nests each containing 4 pipping eggs (set 3 ). The hatching rate of pipping eggs from such nests is sufficiently high ( $>99 \%$ per pipping egg; Rockwell, unpubl. data) that most of the specimens would have left their nests had they not been collected. Embryos and nearhatch goslings from the three sets of collections were preserved in $10 \%$ neutral formalin, transported to the American Museum of Natural History, and transferred to $70 \%$ ethanol.

Because the specimens were collected for other purposes, they were examined non-destructively for gross external deformities. Following especially Romanoff (1972), Hoffman and Albers (1984), Ohlendorf et al. (1986), and Hoffman (1990), the specimens were examined for gross abnormalities of the eyes (including anophthalmia, buphthalmia, cyclopia, exophthalmos, and microphthalmia), legs and wings (e.g., micromelia, amelia, asymmetry, orientation, and duplication), feet (e.g., ectrodactyly and clubfoot), beak (asymmetrical, missing, reduced, crossed), brain (e.g., hydrocephaly and exencephaly) and any general abnormalities of the axial skeleton. A specimen was considered "abnormal" for one or more of these features when the defect was obvious to the naked eye. Descriptions (including a general quantification of the extent of the defect) were recorded for each abnormal specimen. All abnormal specimens were photographed as part of establishing a permanent record. In some cases (see below), we supplemented our visual examination with X-rays.

Although focusing on easily identifiable gross anatomical defects underestimates the frequency of total (including finer level) abnormalities, the approach was used for consistency with previous literature (above) and to allow the examination of more specimens in the fixed time available for this portion of a larger field ecology project. As long as the same criteria are used for other samples, the detection of changes in rates of gross abnormalities and attendant inferences regarding potential contamination will not be biased (cf. Fox et al., 1991b).

Confidence limits for the proportion of abnormalities found among the collected specimens were calculated using sample size and the $F$ distribution following methods in Zar (1999). A modification of that method using the variance of products (see Barrowclough and Rockwell, 1993) was used to calculate the confidence limits of the proportion of abnormalities rescaled to a "per egg present in the nest at hatching" basis (see below).

\section{RESULTS}

We collected 890 abandoned embryos and near-hatch goslings between 1987 and 1996 (sets 1 and 2 above), of which 12 (all found dead) displayed gross external abnormalities of the types described above. This number of abnormalities was too small to allow an evaluation of temporal change, and the entire collection was pooled. The overall proportion of these gross external abnormalities is $1.348 \times$ $10^{-2}$ (95\% confidence limits $0.069 \times 10^{-2}$ to $2.328 \times 10^{-2}$ ). To standardize this to a "per egg" basis, we used an estimate of the proportion of eggs present in the nest at hatching that were abandoned either as near-hatch goslings, pipped eggs, or unpipped eggs containing embryos. This estimate is $2.919 \times$ $10^{-2}$ (with $95 \%$ confidence limits $2.485 \times$ $10^{-2}$ to $2.935 \times 10^{-2} ; \mathrm{n}=6473$; Cooke et al., 1995). Combining these, we arrive at an overall estimate of $3.937 \times 10^{-4}(95 \%$ confidence limits $1.7053 \times 10^{-4}$ to $6.507 \times$ $10^{-4}$ ) as the proportion of eggs displaying obvious external abnormalities for this population of lesser snow geese. Note that this rescaling is with reference to the number of eggs present in the nest at hatching, a value somewhat less than the number of eggs initially laid (see Cooke et al., 1995).

It is possible that scavengers might remove abandoned eggs and near-hatch goslings from hatching nests before we could revisit them. This could reduce the total number of abnormalities found and result in underestimation of the true abnormality rate, especially if, for some reason, abnormal 
abandoned eggs and near-hatch goslings were removed preferentially. To examine the potential magnitude of this bias, we analyzed data from a set of daily monitored nests where all eggs were marked, and on the day the nest was considered to be "hatching" all but one of the eggs was pipped. Revisiting the nest the next day, we found that the marked, originally unpipped egg was missing in fewer than $1 \%$ of the cases $(n=324$; Rockwell, unpubl. data). Thus, although scavenging of abandoned eggs may cause our estimate of abnormality rate to be reduced, we think the extent of the effect is minimal.

Our estimate would also be smaller than the true benchmark rate for the gross deformities we are scoring if some hatchlings with those deformities left the nesting area with their parents. To examine this, we scored the near-hatch goslings removed from the pipped eggs collected from otherwise successful nests (set 3 above) for the same deformities assessed in the 890 abandoned embryos and near-hatch goslings. Among the 624 nearhatch goslings examined, we found none of these deformities. Although a larger sample of these "controls" might have shown an abnormality rate slightly above 0 , we think that our estimate of $3.937 \times 10^{-4}$ per egg in the nest at hatching does not seriously underestimate the true rate of these gross abnormalities for this population of lesser snow geese for the period 1987-1996.

Photographs and brief descriptions of each deformed individual are provided in figures 1 through 13 . We provide a more detailed description in the following. Except where noted, none of the specimens had pipped their egg shell and all other aspects of each specimen was normal.

LPBOO1 (fig. 1). This multilimbed embryo is approximately $75 \%$ the size of a hatchling and has numerous deformities. It is missing the posterior portions of the frontal bones, the majority of the parietal and squamosal bones, and the bulk of the occipital complex proximal to the foramen magnum. Whether these skull "defects" reflect true deformities or simply incomplete ossification related to a younger age (assumed from size) is not known. There are two separate upper mandibles with the right one being half the length of the left. The lower mandible is also duplicated but fused medially. It is the same length as the left upper mandible. There are two normal-sized eye sockets and eyes on the lateral sides of the head and a single fused medial socket in the front of the skull that contains two eyes. The specimen displays extreme scoliosis. The left- and rightmost legs are near normal. The central third "leg" is comprised of separate, normal feet and tarsometatarsi. Proximal to the lateral condyle, there are two separate tibiotarsi that are encased in a single skin sheath. Because we did not wish to destroy the specimen to make a stained skeletal preparation, we examined LPB001 further with X-rays. From those (fig. 2 ), it is clear that there are two vertebral columns, two femurs, and the bulk of two pelvic girdles. Interestingly, there is no indication of more than two wings. Broom (1897) reported on a chick with four legs and wings which, upon dissection, revealed the presence of two complete vertebral columns. Diard (1897), in contrast, reported on a fourlegged duck which possessed only one vertebral column. In that case, the second pair of (stunted) legs originated directly from the vertebral column, immediately anterior to the first caudal vertebra. Tornier (1901) also reports on several multilegged chicks and ducks that have single vertebral columns.

LPBOO2 (fig. 3). This hatchling-size specimen displays duplication of both upper and lower mandibles with the lower ones being medially fused except for the most distal $25 \%$ of their length. There are two normalsized eye sockets and eyes on the lateral sides of the head and a single fused medial socket in the front of the skull that contains two eyes. X-ray evaluation reveals no vertebral column duplication posterior to the skull (fig. 4).

LPBOO3 (fig. 5). The fully formed left eye has developed external to the cranial socket (monoexophthalmos). A sibling of this individual was also abandoned but displayed no abnormalities. Both the specimen and its sibling had pipped their shells.

LPBO04 (fig. 4). The upper and lower mandibles are symmetrically reduced to approximately $65 \%$ of their normal size.

LPBO05 (fig. 7). This specimen displays several deformities. Both feet are clubbed, 

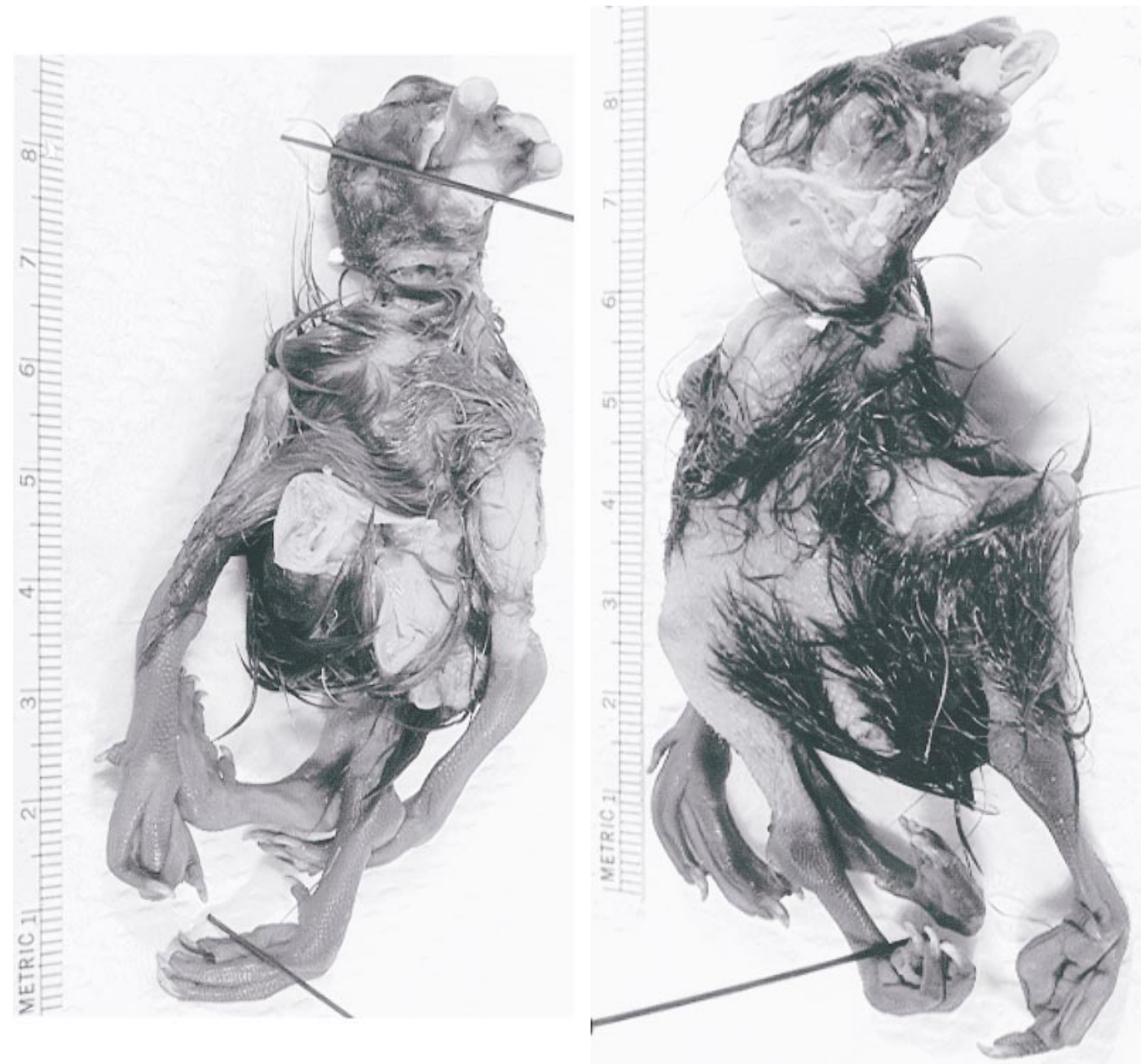

Fig. 1. Multilimbed embryo (LPB001) that also displays numerous deformities of the head. Ventral (left) and dorsal (right) views of the head region.

with the left being more extreme. The third digit of the left foot includes only a terminal phalanx, while the second and fourth digits are reduced in overall length by approximately $50 \%$. The digits of the right foot are reduced in overall length to approximately $50 \%$. The distal portion of both tarsometatarsi are rotated so the feet are oriented inward by nearly $90^{\circ}$. The head (not shown) is asymmetrical, with the left eye socket displaced anteriorly toward the beak with an apparent reduction in the anterior portion of the left frontal bone. The upper and lower mandibles are rotated $45^{\circ}$ to the specimen's right and are slightly crossed.
LPBO06 (fig. 8). The lower mandible is reduced to approximately $25 \%$ of normal size. Its tip is asymmetrical, being both larger on the right and rotated outward in that direction. The upper mandible is of normal length but the nasal apertures are raised from the surface.

LPBOO7 (fig. 9). The upper and lower mandibles are reduced to approximately $25 \%$ of their normal size and are slightly crossed. They have a pyramidal shape.

LPBOO8 (fig. 10). The head is asymmetrical with a reduction in the left anterior frontal bone and expansion of the right posterior frontal and right squamosal bones. The upper 


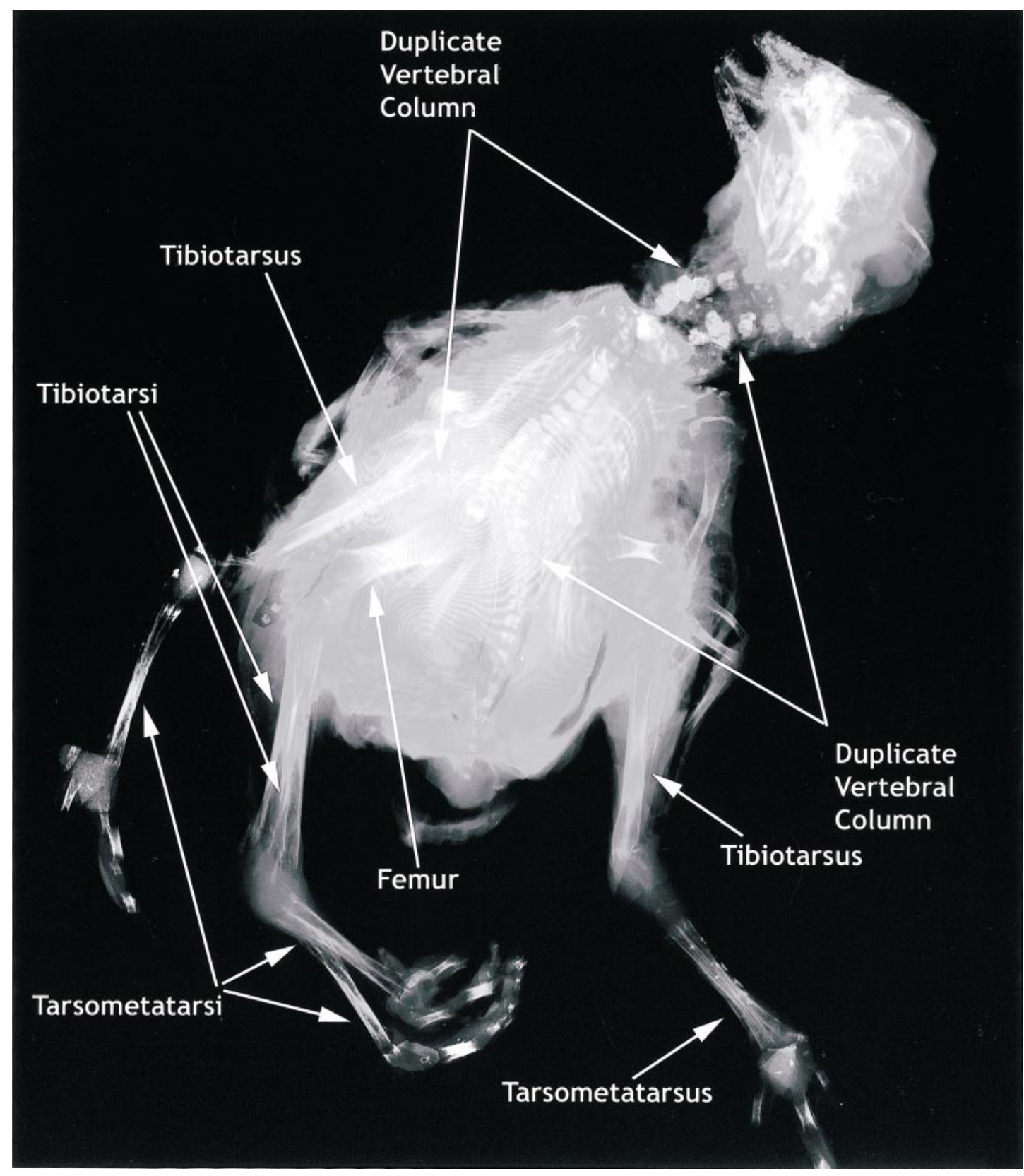

Fig. 2. X-ray of LPB001 showing duplication of vertebral structures.

and lower mandibles are symmetrically reduced to approximately $75 \%$ of normal length.

LPBO09 (fig. 11). The lower mandible is reduced to approximately $50 \%$ of normal length, with the tip asymmetrically large on the left. The anterior frontal bones are sloped rather than rounded, making the specimen seem to have no forehead.

LPBO10 (fig. 12). The specimen is missing the parietal, occipital complex, and posterior portions of the squamosal bones of the skull. 

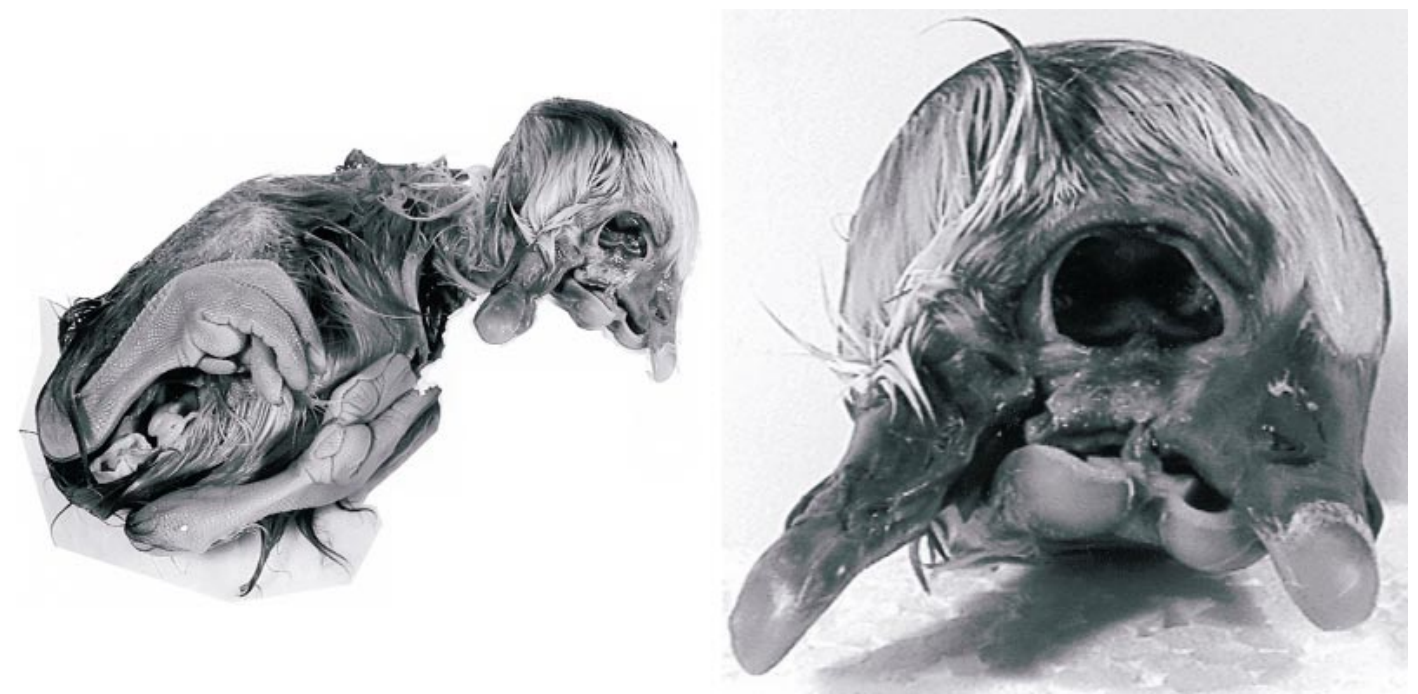

Fig. 3. Specimen LPB002 displaying duplication of mandibles and fusion of medial eye socket. Entire specimen (left) and details of head region (right).

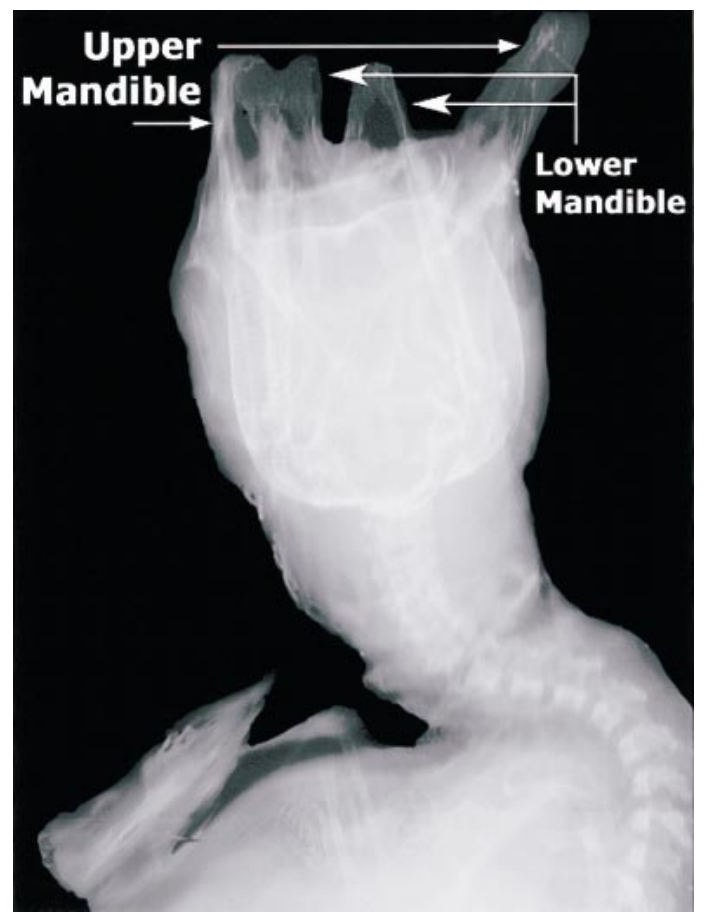

Fig. 4. X-ray of LPBO02 showing that there is but a single vertebral column.
Prior to preservation, more than $30 \%$ of the brain was externalized.

LPBO11 (fig. 13). Both upper and lower mandibles are reduced to approximately $50 \%$ of normal length. The specimen had pipped its shell.

LPBO12 (not shown). This abandoned embryo was approximately $50 \%$ normal size and decayed. The lower mandible was only approximately $75 \%$ the size of the upper mandible.

\section{DISCUSSION}

The rate of gross external abnormalities among snow geese at La Pérouse Bay is $3.937 \times 10^{-4}$ per egg $(95 \%$ confidence limits $1.7053 \times 10^{-4}$ to $6.507 \times 10^{-4}$ ). This value is near the upper end of the range of rates $\left(8.0 \times 10^{-6}\right.$ to $\left.4.8 \times 10^{-4}\right)$ reported for similar deformities among California Gulls ( $\mathrm{La}$ rus californicus), Herring Gulls, and Sooty Terns (Sterna fuscata) sampled in putatively uncontaminated habitats (Threlfall, 1968; Austin, 1969; Smith and Diem, 1971). It is also within the range of abnormality rates re- 


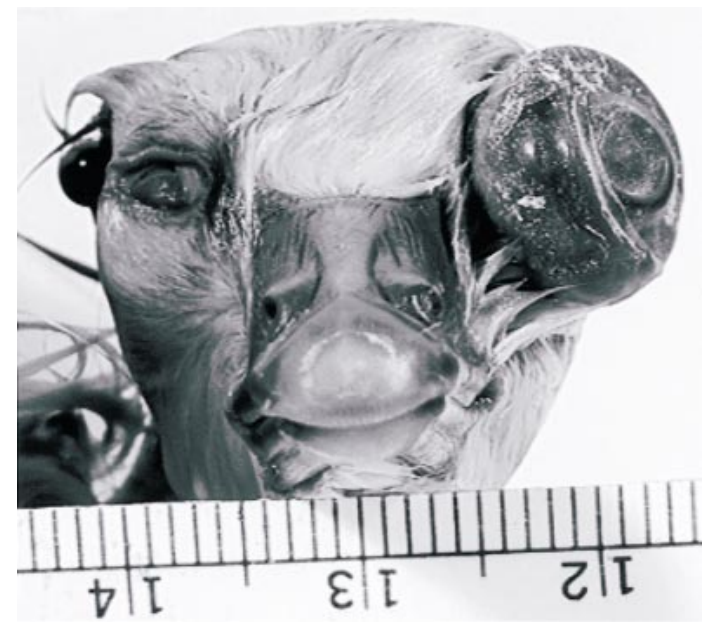

Fig. 5. Externalized eye of specimen LPB003.

ported for double-crested cormorants ( 0 to $5.7 \times 10^{-4}$ ) from putatively minimally or uncontaminated reference sites (Fox et al., 1991b; Rykman et al., 1998). Note that all of these other estimates were based only on abnormalities observed among surviving hatchlings and near-fledging juveniles. Owing to mortality associated with abnormalities in embryos and near-hatch juveniles (classes excluded in their estimates but included in ours), their estimates are expected to be lower than ours, and even more so for the double-crested cormorants that included only beak defects (Fox et al., 1991b). Allowing for this, our estimate certainly falls within the range expected for minimally or uncontaminated habitats.

Consistently, our estimate is substantially below the rates of $1.0 \times 10^{-3}$ to $1.3 \times 10^{-2}$ gross external abnormalities per egg reported for Common and Roseate Terns (Sterna hirundo and $S$. dougalli) sampled off the eastern tip of Long Island and estimated at a time when chemical contamination was suspected in the area (Hays and Risebrough, 1972). It is also well below the estimates of $1.5 \times 10^{-2}$ and $2.5 \times 10^{-2}$ gross abnormalities per egg for Double-crested Cormorants and Caspian Terns, respectively, calculated from data on the same abnormalities we scored that was presented in Ludwig et al.'s (1996) study of the effects of chemical contamination on these species in the Great Lakes. These comparisons have the advantage that the data,

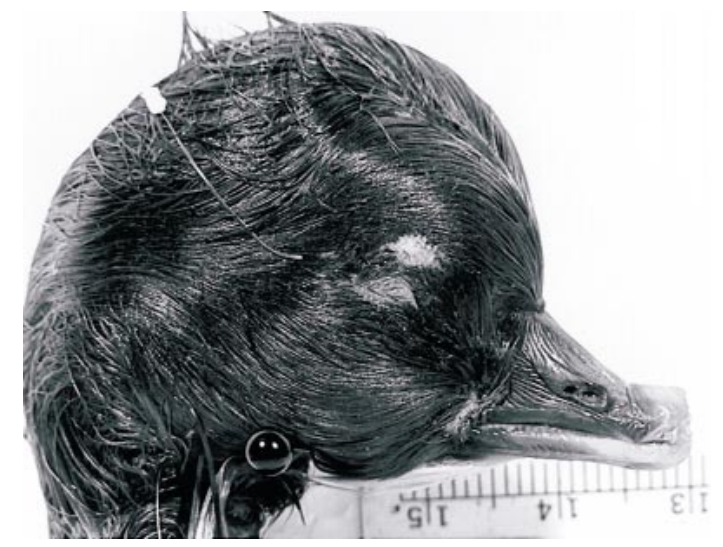

Fig. 6. Symmetrically reduced mandibles of specimen LPB004.

like ours, included abnormalities among embryos and near-hatch juveniles. Even though our estimate for the rate of gross external abnormalities is well below that for a contaminated habitat and within the range of rates expected for minimally or uncontaminated habitats, we prefer to view our estimate as a current benchmark rather than a true, contaminant-free baseline value for this species. Given the agricultural areas where snow geese winter and forage in the spring and fall (Jefferies et al., 2002), it is possible that some level of contaminants are carried north but appear to be below any threshold of biological (teratogenic) impact.

Even though the abnormality rate for snow geese appears to lie within a range consistent with minimal contamination, the distribution of the types of gross abnormalities is curious. Among the 12 abnormal specimens, there are 10 defects involving the beak and only 4 involving the eye (this includes defects in both for 3 specimens with multiple abnormalities). This is in marked contrast to the relative distribution of spontaneous occurrences of these gross deformities in chickens, where beak deformities are only half as frequent as eye deformities (Romanoff, 1972). Whether this is a species-specific difference cannot be known until spontaneous rate data for more species are available. In the interim, however, note that although the current rate of abnormality for snow geese is not sufficient to infer the presence or action of toxicants, an excess of bill deformities was reported for dou- 


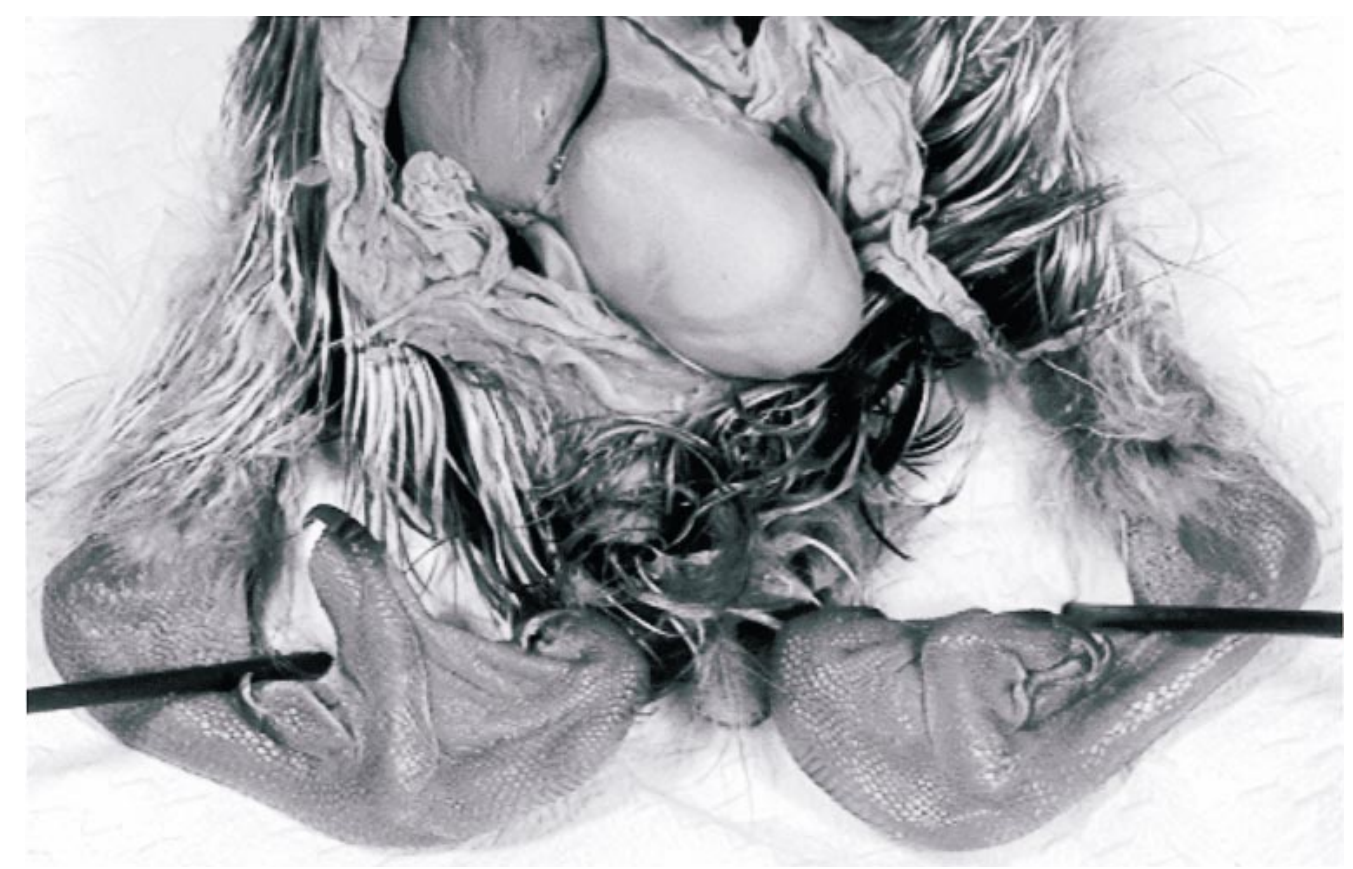

Fig. 7. Clubbed feet of specimen LPB005.

ble-crested cormorants in the Great Lakes during a period where contamination was elevated at several locations (cf. Fox et al., 1991b). Defects involving the beak and not the eye are often a product of type 1 teratogenesis (Hoffman, 1990) and for agriculturally related compounds are reported more frequently in association with the action of insecticides (especially organophosphate ones) than herbicides (Hoffman and Albers,

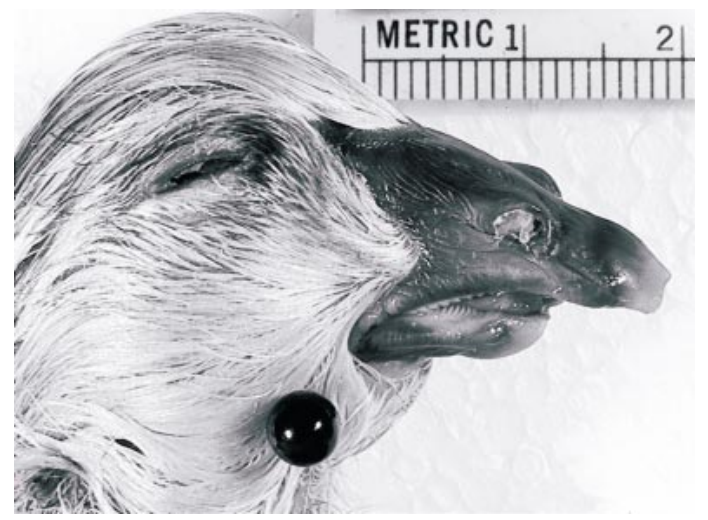

Fig. 8. Asymmetrically reduced lower mandible of specimen LPB006.
1984). Future studies should closely monitor the relative distributions of types of abnormalities as well as assess any change in the rate.

Our primary purpose was to establish a current benchmark of gross abnormalities for lesser snow geese to which future estimates from this or other geographically distinct nesting populations of this species could be

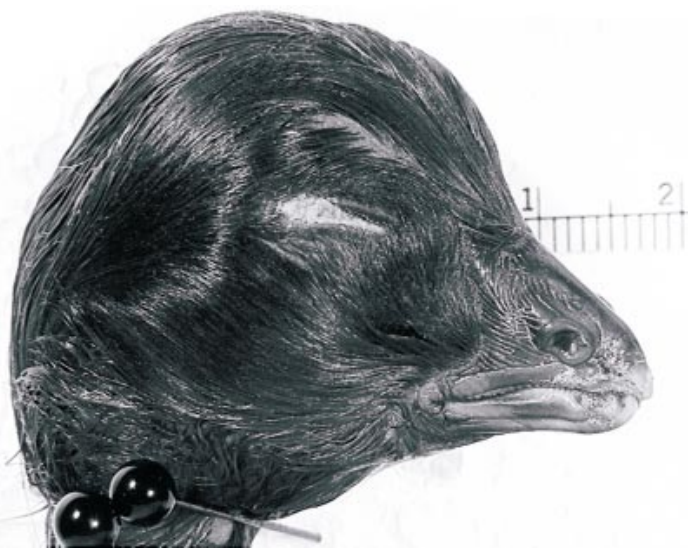

Fig. 9. Symmetrically reduced mandibles of specimen LPB007. 


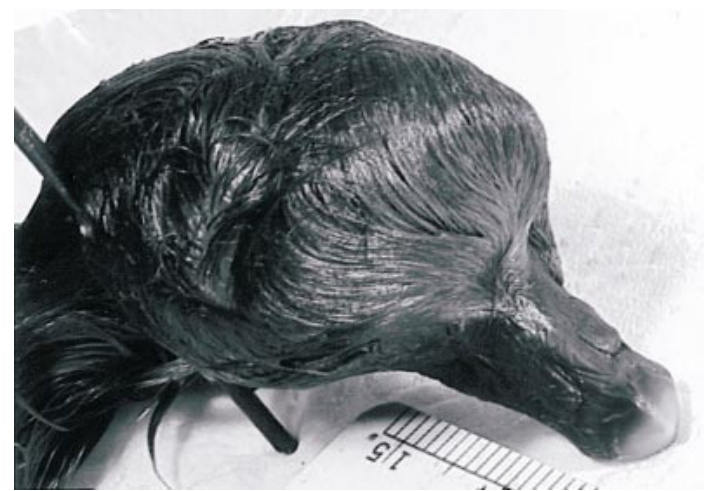

Fig. 10. Skull abnormalities of specimen LPB008.

compared. Assuming data are collected in the same fashion, those comparisons would be statistically more powerful if based simply on the rate of abnormalities among abandoned embryos and near-hatch goslings at hatched nests since the rescaling to a per egg basis requires incorporating the sampling error associated with the conversion factor (see Methods). Given this and using the upper 95\% confidence limit of the estimate of abnormalities per abandoned embryo and nearhatch gosling of $2.328 \times 10^{-2}$ as a point of reference, it can be calculated that finding only 36 abnormal specimens for the same sample size of 890 would be sufficient to yield an estimated abnormality rate $(4.044 \times$ $10^{-2}$ ) that would be significantly higher than the current benchmark of $1.348 \times 10^{-2}$. Using a smaller sample size of 100 abandoned embryos and near-hatch goslings would require finding 7 abnormal specimens and a

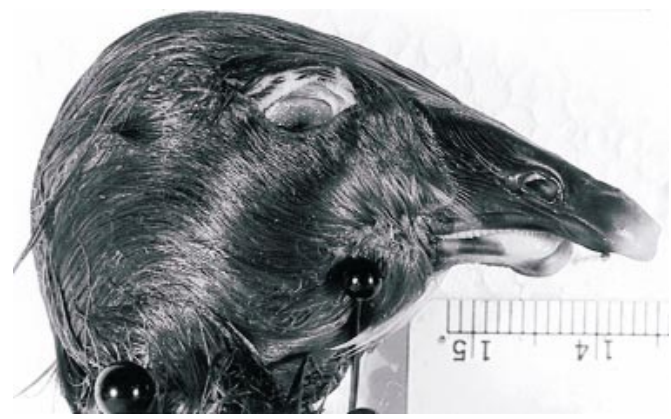

Fig. 11. Asymmetrical reduction in lower mandible of specimen LPB009 that also displays misshapen anterior frontal bones.

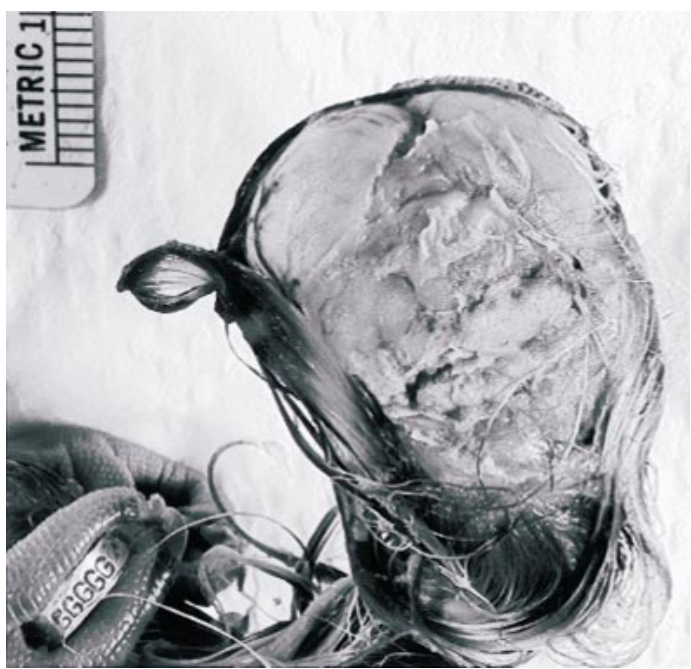

Fig. 12. Externalized brain of specimen LPB010 that is missing several bones of the skull.

rate of $7 \times 10^{-2}$ to demonstrate a significant increase.

In either case, it would be reasonable to infer that some factor or set of factors had changed over time or differed between the samples. The most likely candidates would include increased inbreeding, decreased (or altered) nutritional status of the female producing the eggs, altered climatic factors, or the increases in toxicant(s) above a threshold of teratogenic action (Romanoff, 1972; Fox et al., 1991b). For this species, population levels are so high (Abraham and Jefferies, 1997) and gene flow is sufficient (Rockwell and Barrowclough, 1987) that inbreeding is

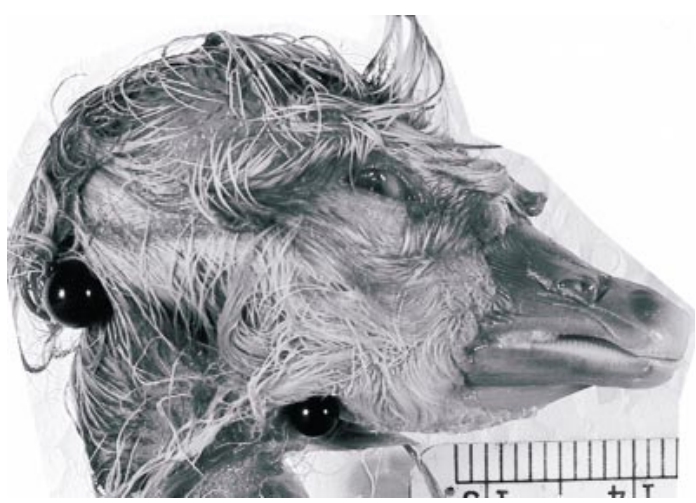

Fig. 13. Symmetrically reduced upper and lower mandibles of LPB011. 
not likely to become a problem. Climatic changes would most likely require depressions of temperature (Romanoff, 1972), changes that are inconsistent with current trends and projections for the Hudson Bay and Foxe Basin regions (Skinner et al., 1998). Part of the explosive growth of the Mid-continent population of lesser snow geese is related to an increasing nutritional subsidy the birds are acquiring through increased use of agricultural areas of the Midwest (Jefferies et al., 2002). Unless current agricultural practices are greatly altered, it is unlikely that female snow geese arriving in the Hudson Bay and Foxe Basin region of Canada will suffer nutritional deficits.

This increased use of agricultural lands for wintering and both spring and fall staging is, however, the potential route for increased exposure to and dietary intake of agricultural compounds (e.g., pesticides, fungicides, and herbicides) that could reach levels in eggs that would be reflected in increased rates of gross developmental abnormalities. For this species, then, significant increases (or differences with respect to other colonies) in the rates of gross abnormalities among embryos and near-hatch goslings abandoned at hatched nests should trigger a serious consideration of toxicant screening with a special emphasis on agriculture-related compounds. If the high proportion of beak abnormalities persists, then compounds with known type 1 teratogenic action such as some organophosphate insecticides should be initially suspected.

Our more general goal is to encourage others to follow Fox et al.'s (1991b) suggestion to collect and use data on abnormalities as a bio-monitoring tool to assess changes in environmental conditions that are sufficient to have biological impact. As part of that, it is likely that there are data that will provide estimates of deformity rates hidden in the field notes of many researchers and likely in the unpublished reports of many federal, state, provincial and nongovernmental organizations. Part of our purpose here is to encourage those in possession of such data to either publish them or at least make them available to a broader audience. It is our view that by compiling data, even from studies that in and of themselves are too small to publish formally, we will accumulate a database of historic and current deformity rates that will aid in a variety of conservation and management issues. To that end, we offer our web site (http://research.amnh.org/users/rfr/ hbp) as a place where such data and images can be submitted. They will be posted and made available to anyone interested. When publishing or submitting such data, it is important to either scale the rates to a common basis (e.g., deformities per egg) or clearly indicate the basis. It is also crucial to include sample sizes or estimates of confidence limits.

With certain limitations, we are also willing to curate and store specimens displaying abnormalities. Like all specimens at the American Museum of Natural History, they, like the ones reported here, will be available for examination to all bona fide researchers. Owing to U.S. Federal regulations, International Treaties and AMNH policies, donated specimens must have been collected and, if applicable, exported under valid permits. Copies of all relevant documents, including collecting and exportation permits and a letter donating the specimens to the American Museum of Natural History, must be provided. To avoid problems, it is essential that we be contacted before any specimens are shipped.

\section{ACKNOWLEDGMENTS}

We appreciate comments from Ken Abraham, Graham Cooch, Paul Flint, Glen Fox, Helen Hays, David Hoffman, and Pierre Mineau. This work was done under the auspices of the Hudson Bay Project and with the cooperation of Wapusk National Park. Funding for the Hudson Bay Project is provided in part by the Arctic Goose Joint Venture, the Central and Mississippi Flyway Councils, the Department of Indian and Northern Affairs (Canada), Ducks Unlimited, the City University of New York, and the Olive Bridge Fund.

\section{REFERENCES}

Abraham, K.F., and R.L. Jefferies. 1997. High goose populations: causes, impacts and implications. In B. Batt (editor), Arctic ecosystems in peril: report of the Arctic Goose Habitat 
Working Group: 7-72. Washington, DC: Arctic Goose Joint Venture, Canadian Wildlife Service, and U.S. Fish and Wildlife Service.

Ankney, C.D., and C.D. MacInnes. 1978. Nutrient reserves and reproductive performance of female lesser snow geese. Auk 95: 459-471.

Austin, O.L. 1969. Extra toes on a Sooty tern chick. Auk 86: 352.

Barrowclough, G.F., and R.F. Rockwell. 1993. Variance in lifetime reproductive success: estimation based on demographic data. American Naturalist 141: 281-295.

Blus, L.J., M.J. Melancon, D.J. Hoffman and C.J. Henny. 1998. Contaminants in eggs of colonial waterbirds and hepatic cytochrome P450 enzyme levels in pipped tern embryos, Washington State. Archives of Environmental Contamination and Toxicology 35: 492-497.

Broom, R. 1897. On the anatomy of a fourwinged chick. Transactions of the Natural History Society, Glasgow 4: 315-316.

Cooke, F., R.F. Rockwell and D.B. Lank. 1995. The snow geese of La Pérouse Bay-natural selection in the wild. New York: Oxford, 297 pp.

Craves, J.A. 1994. Passerines with deformed bills. North American Bird Bander 19: 14-18.

Custer, T.W., C.M. Custer, R.K. Hines, S. Gutreuter, K.L. Stromborg, P.D. Allen, and M.J. Melancon. 1999. Organochlorine contaminants and reproductive success of double-crested cormorants from Green Bay, Wisconsin. Environmental Toxicology and Chemistry 18: 1209-1217.

Diard. 1897. Canard a quatre pattes (monstre pygomèle). Bulletin Société d'Histoire Naturelle d'Autun 10: 226-230.

Flickenger, E.L., and E.G. Bolen. 1979. Weights of lesser snow geese taken on their winter range. Journal of Wildlife Management 43: 531-533.

Fox, G.A., and D.V. Weseloh. 1987. Colonial waterbirds as bioindicators of environmental contamination in the Great Lakes. ICBP Technical Publications 6: 209-216.

Fox, G.A., M. Gilbertson, A.P. Gilman, and T.J. Kubiak. 1991a. A rationale for the use of colonial fish-eating waterbirds to monitor for the presence of developmental toxicants in Great Lakes fish. Journal of Great Lakes Research 17: $151-152$.

Fox, G.A., B. Collins, E. Hayakawa, D.V. Weseloh, J.P. Ludwig, T.J. Kubiak, and T.C. Erdman. 1991b. Reproductive outcomes in colonial fisheating birds: a biomarker for developmental toxicants in Great Lakes food chains. II. Spatial variation in the occurrence and prevalence of bill defects in young double-crested cormorants in the Great Lakes, 1979-1987. Journal of Great Lakes Research 17: 158-167.

Geisy, J.P., J.P. Ludwig, and D.E. Tillitt. 1994. Deformities in birds of the Great Lakes region-assigning causality. Environmental Science Technology 28: 128-135.

Gilbertson, M., R.D. Morris and R.A. Hunter. 1976. Abnormal chicks and PCB residue levels in eggs of colonial birds on the lower Great Lakes (1971-73). Auk 93: 434-442.

Gilbertson, M., J.E. Elliott, and D.B. Peakall. 1987. Seabirds as indicators of marine pollution. ICBP Technical Publication 6: 231-248.

Gilbertson, M., T. Kubiak, J. Ludwig, and G. Fox. 1991. Great lakes embryo mortality, edema and deformities syndrome (GLEMEDS) in colonial fish-eating birds: similarity to chick edema disease. Journal of Toxicology and Environmental Health 33: 455-520.

Gotchfeld, M. 1975. Developmental defects in common terns of western Long Island, New York. Auk 92: 58-65.

Hays, H., and R.W. Risebrough. 1972. Pollutant concentrations in abnormal young terns from Long Island Sound. Auk 89: 19-35.

Hoffman, D.J. 1990. Embryotoxicity and teratogenicity of environmental contaminants to bird eggs. Reviews of Environmental Contamination and Toxicology 115: 39-89.

Hoffman D.J., and P.H. Albers. 1984. Evaluation of potential embryotoxicity and teratogenicity of 42 herbicides, insecticides, and petroleum contaminants to mallard eggs. Archives of Environmental Contamination and Toxicology 13: 15-27.

Hoffman, D.J., B.A. Rattner, L. Sileo, D. Docherty, and T.J. Kubiak. 1987. Embryotoxicity, teratogenicity and aryl hydrocarbon hydroxylase activity in Forster's terns on Green Bay, Lake Michigan. Environmental Research 42: 176-184.

Hoffman, D.J., H.M. Ohlendorf, and T.W. Aldrich. 1988. Selenium teratogenesis in natural populations of aquatic birds in central California. Archives of Environmental Contamination and Toxicology 17: 519-525.

Hoffman, D.J., B.A. Rattner, I. Scheunert, and F. Korte. 2001. Environmental contaminants. In R.F. Shore and B.A. Rattner (editors), Ecotoxicology of Wild Mammals: 1-48. New York: Wiley.

Jefferies, R.L., H.A.L. Henry, and K.F. Abraham. 2002. Agricultural nutrient subsidies to migratory geese and change in Arctic coastal habitats. In G.A. Polis and M.E. Power (editors.), Food Webs at the Landscape Level. Chicago: University of Chicago Press.

Landauer, W. 1967. The Hatchability of Chicken 
Eggs as Influenced by Environment and Heredity. Storrs: University of Connecticut, 315pp.

Larson, J.M., W.H. Karasov, L. Sileo, K.L. Stromborg, B.A. Hanbidge, J.P. Giesy, P.D. Jones, D.E. Tillitt, and D.A. Verbrugge. 1996. Reproductive success, developmental anomalies, and environmental contaminants in double-crested cormorants (Phalacrocorax auritus). Environmental Toxicology and Chemistry 15: 553-559.

Ludwig, J.P., H.J. Auman, D.V. Wesloh, G.A. Fox, J.P. Giesy, and M.E. Ludwig. 1995. Evaluation of the effects of toxic chemicals in Great Lakes cormorants: Has causality been established? Colonial Waterbirds 18: 60-69.

Ludwig, J.P., H. Kurita-Matsuba, H.J. Auman, M.E. Ludwig, C.L. Summer, J.P. Giesy, D.E. Tillitt, and P.D. Jones. 1996. Deformities, PCBs and TCDD-equivalents in double-crested cormorants (Phalacrocorax auritus) and Caspian terns (Hydroprogne caspia) of the upper Great Lakes 1986-1991: testing a cause-effect hypothesis. Journal of Great Lakes Research 22: 172-197.

McGinn, A.P. 2000. Phasing out persistent organic pollutants. In Worldwatch Institute State of the World 2000: 79-100. New York: Norton.

Nisbet, I.C.T. 1998. Trends in concentrations and effects of persistent toxic contaminants in the Great Lakes: their significance for inferring cause-effect relationships and validating management actions. Environmental Monitoring and Assessment 53: 3-15.

Nogales, M., A. Martin, and F. Zino. 1990. Bill malformation of juvenile Corey's shearwater (Calonectris diomedea borealis) on Selvagem Grande. Bocogiana 139: 1-5.

Officer, C., and J. Page. 2000. Earth and YouTales of the Environment. Portsmouth, N.H.: PE Randall, 254 pp.

Ohlendorf, H.M., D.J. Hoffman, M.K. Saiki, and T.W. Aldrich. 1986. Embryonic abnormalities of aquatic birds: apparent impacts of selenium from irrigation drainwater. The Science of the Total Environment 52: 49-63.

Ohlendorf, H.M., A.W. Kilness, J.L. Simmons, R.K. Stroud, D.J. Hoffman, and J.F. Moore. 1988. Selenium toxicocis in wild aquatic birds. Journal of Toxicology and Environmental Health 24: 67-92.

Peakall, D.B., and H. Boyd. 1987. Birds as bioindicators of environmental conditions. ICBP Technical Publication 6: 113-118.
Pimm, S.L. 2001. The World According to Pimm. New York: McGraw-Hill, 285 pp.

Rockwell, R.F., and G.F. Barrowclough. 1987. Gene flow and the genetic structure of populations. In F. Cooke and P.A. Buckley (editors), Avian Genetics: 223-255. London: Academic Press.

Romanoff, A.L. 1972. Pathogenesis of the Avian Embryo. New York: Wiley Interscience, 476 pp.

Ryder, J.P., and D.J. Chamberlain. 1972. Congenital foot abnormality in the ring-billed gull. Wilson Bulletin 84: 342-344.

Rykman, D.P., D.V. Weseloh, P. Hamr, G.A. Fox, B. Collins, P.J. Ewins, and R.J. Norstrom. 1998. Spatial and temporal trends in organochlorine contamination and bill deformities in doublecrested cormorants (Phalacrocorax auritus) from the Canadian Great Lakes. Environmental Monitoring and Assessment 53: 169-195.

Skinner, W.R., R.L. Jefferies, T.J. Carleton, R.F. Rockwell and K.F. Abraham. 1998. Prediction of reproductive success and failure in lesser snow geese based on early season climatic variables. Global Change Biology 4: 3-16.

Smith, J., and K.L. Diem. 1971. Incidence of deformed bills in gulls (Larus californicus). Auk 88: 435 .

Threlfall, W. 1968. A herring gull chick (Larus argentatus) with an abnormal bill. Auk 85: 506-508.

Tornier, G. 1901. Neues über das natürliche Enstehen und experimentelle Erzeugen überzählinger und Zwillungsbildungen. Zoologischer Anzeiger 24: 488-504.

Volponi, S. 1996. Bill deformity in a pygmy cormorant (Phalacrocorax pygmeus) chick. Colonial Waterbirds 19: 147-148.

White, D.H., C.A. Mitchell, E.J. Kolbe, and J.M. Williams. 1982. Parathion poisoning of wild geese in Texas. Journal of Wildlife Diseases 18: 389-391.

Yamashita, N., S. Tanabe, J.P. Ludwig, H. Kurita, M.E. Ludwig, and R. Tatsukawa. 1993. Embryonic abnormalities and organochlorine contamination in double-crested cormorants (Phalacrocorax auritus) and Caspian terns (Hydroprogne caspia) from the upper Great Lakes in 1988. Environmental Pollution 79: 163-173.

Zar, J.H. Biostatistical analysis, 4 ${ }^{\text {th }}$ Edit. 1999. New York: Prentice Hall, 663 pp. 